\title{
Is patient-centredness in European hospitals related to existing quality improvement strategies? Analysis of a cross-sectional survey (MARQulS study)
}

\author{
0 Groene, ${ }^{1}$ M J M H Lombarts, ${ }^{2}$ N Klazinga, ${ }^{2} J$ Alonso, ${ }^{3}$ A Thompson, ${ }^{3}$ R Suñol'
}

\begin{abstract}
${ }^{1}$ Avedis Donabedian Institute, Autonomous University of Barcelona, and CIBER Epidemiology and Public Health (CIBERESP), Barcelona, Spain; ${ }^{2}$ Academic Medical Center, Department of Social Medicine, University of Amsterdam, Amsterdam, the Netherlands:

${ }^{3}$ School of Social and Political Studies, University of Edinburgh, Scotland
\end{abstract}

Correspondence to:

0 Groene, Avedis Donabedian University Institute, Autonomous University of Barcelona,

Provenza 293 Pral, 08037

Barcelona, Spain; ogroene@ fadq.org

Accepted 12 November 2008

\begin{abstract}
Background: There is growing recognition of patients' contributions to setting objectives for their own care, improving health outcomes and evaluating care.

Objective: To quantify the extent to which European hospitals have implemented strategies to promote a patient-centred approach, and to assess whether these strategies are associated with hospital characteristics and the development of the hospital's quality improvement system.
\end{abstract}

Design: Cross-sectional survey of 351 European hospital managers and professionals.

Main outcome measures: Patients' rights, patient information and empowerment, patient involvement in quality management, learning from patients, and patient hotel services at the hospital and ward level were assessed. The hypothesis that the implementation of strategies to improve patient-centredness is associated with hospital characteristics, including maturity of the hospital's quality management system, was tested using binary logistic regression.

Results: In general, hospitals reported high implementation of policies for patients' rights (85.5\%) and informed consent (93\%), whereas strategies to involve patients $(71 \%)$ and learn from their experience (66\%) were less frequently implemented. For 13 out of 18 hospital strategies, institutions with a more developed quality improvement system consistently reported better results (percentage differences within maturity classification ranged from $12.4 \%$ to $46.6 \%)$. The strength of association between implementation of patient-centredness strategies and the quality improvement system, however, seemed lower at the ward than at the hospital level. Some associations (OR 2.1 to 5.1) disappeared or were weaker after adjustment for potential confounding variables (OR 2.2 to 3.7).

Conclusions: Although quality improvement systems seem to be effective with regard to the implementation of selected patient-centredness strategies, they seem to be insufficient to ensure widespread implementation of patient-centredness throughout the organisation.

There is growing recognition in the literature of the contribution patients can make to setting objectives for their own care, ${ }^{12}$ improving health outcomes, ${ }^{3}{ }^{4}$ or evaluating healthcare. ${ }^{5}$ Given patients' and the public's expectations, the nature of chronic disease management, and the potential economic benefits of involving citizens and patients in their care, there is relatively broad agreement on the need for a patient-centred approach in health service delivery. ${ }^{67}$
The concept of patient-centredness has a long tradition in medicine and health services research, going back to the 1950s. At that time, the excessive focus of medical care on disease processes rather than the illness experience raised many concerns and initiated calls for a more holistic biopsychosocial model of health. ${ }^{89}$ A universally accepted definition of patient-centredness, however, does not exist. ${ }^{10}$ For example, the Institute of Medicine defines it $\mathrm{as}^{7}$ :

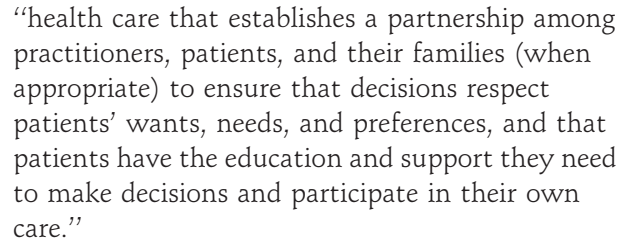

Stewart, ${ }^{11}$ in her definition, emphasises exploring the patients' main concerns, emotional, and information needs, finding common ground, and enhancing the continuing relationship between patient and doctor. The Picker approach to assessing patients' experience defines eight dimensions of patient-centred care $^{12}$ :

- access;

- respect for patients' values, preferences and expressed needs;

- coordination and integration of inpatient services;

- information, communication, and education; physical comfort;

- emotional support and alleviation of fear and anxiety;

- involvement of family and friends;

- transition and continuity after discharge.

Based on a study of primary care delivery, Little et al summarised patient-centredness as follows ${ }^{13}$ :

\footnotetext{
"There are at least three important and distinct domains of patient-centredness: communication, partnership, and health promotion."
}

Although a patient-centred approach is widely advocated, its implementation in practice is limited and related to characteristics of both doctors and patients. ${ }^{14-16}$ There is evidence that patients frequently do not receive important information on their condition and options for self-management, and that there is insufficient involvement of patients in developing quality goals. ${ }^{17}{ }^{18}$ Moreover, surveys frequently report patients' dissatisfaction with the way services are organised in the hospital, ${ }^{19}$ the lack of time for consultations, and 
difficulties in understanding what doctors tell them. ${ }^{20}$ These shortcomings of hospital services on measures of patientcentredness may be explained partly by the lack of systematic evaluation and integration of activities into the hospital's quality management system: although hospital quality management systems usually address generic issues through policies on patients' rights and informed choice, and conduct surveys of patients' views, patients' involvement in decisions concerning their disease, or in the design of new services, seems not yet to have become a focus of hospital quality management systems. ${ }^{21}$

In order to promote patient-centredness, baseline information is required on the implementation of related strategies and on existing implementation gaps. Moreover, clarification is needed whether the domains of patient-centredness should be promoted as an integral part of existing quality management systems, or through the development of new, separate systems. We therefore examined the implementation of strategies applied in European hospitals to improve patient-centredness, and their relationship with existing quality management systems. Our specific objectives were to:

- quantify the extent to which European hospitals have implemented strategies to promote a patient-centred approach

- determine whether the adoption of these strategies is associated with hospital characteristics and the maturity of the hospital's quality improvement system.

\section{MATERIAL AND METHODS}

\section{Setting}

Our study was based on a cross-sectional survey of hospitals in Belgium, the Czech Republic, France, Ireland, the Netherlands, Poland, Spain, and the UK. Acute care hospitals with more than 100 beds were identified by country coordinators, and hospitals were randomly selected from this group of centres. Selected hospitals were contacted to participate in the study and to complete an electronic questionnaire. The sampling characteristics and hospital recruitment criteria used in this study are explained fully elsewhere. ${ }^{22}$

\section{Data collection}

The questionnaire included four sections: section 1 (strategic level, sent to the chief executive officer or quality manager), which included a general description of the hospital's structures and quality management systems, and sections 2-4 (ward level, sent to the head of the department), which included quality measures related to the management of acute myocardial infarction (AMI), appendicitis and deliveries (details about the questionnaire design are described elsewhere in this supplement ${ }^{22}$ ). Data on deliveries will be presented in a separate paper.

The questionnaire design was based on a review of quality improvement questionnaires, literature reviews, analysis of accreditation manuals and additional studies carried out within the Methods of Assessing Response to Quality Improvement Strategies (MARQuIS) project. ${ }^{23-25}$ Data collection took place between April and August 2006. The questionnaire was translated into five languages (Czech, Dutch, French, Polish, Spanish) based on a protocol for forward and backward translation.

\section{Operationalisation of patient-centredness}

We assessed patient-centredness at two levels: the hospital management level and the ward level. Patient-centredness at the hospital level was operationalised according to the following main domains, identified through a literature search: patients' rights; patient information and empowerment; patient involvement in quality management; learning from patients; and patient hotel services. For each domain we included items that were evaluated as most relevant according to the conceptualisation in the literature. We excluded the domain "patient involvement in quality management" from operationalisation at the ward level. Because our study did not involve data collection at the level of individual patients, we excluded domains such as reduction in anxiety and emotional support from our operationalisation of patient-centredness.

\section{Quality improvement maturity}

In order to test associations between patient-centredness (dependent variable) and hospital characteristics and the development of the hospital's quality management system (independent variables), we classified hospital quality improvement maturity in this study. This classification integrates seven dimensions reflecting overall developmental phases (maturity) of the hospitals' quality improvement system: policy, planning and documents (20 items), leadership (36 items), structure (19 items), general quality improvement activities (8 items), specific quality improvement activities (20 items), patient involvement in quality management ( 6 items) and accountability (4 items). This classification does not include ward-level data. The process of developing and validating the maturity classification and its scoring and cut-off points are described in detail elsewhere in this supplement. ${ }^{26}$

\section{Statistical analysis}

For this study we excluded the patient-centredness items included in the original maturity classification to avoid relating the same items, thus reducing the number of items from 113 to 95. Cronbach's $\alpha$ (before: 0.75 , after 0.78 ), mean and standard deviation changed only slightly. We observed only minor changes in the distribution of hospitals in quartiles $(\kappa$ $=0.826, \mathrm{p}<0.001$ )

For dependent variables (strategies to improve patientcentredness at the hospital level and the ward level) we used the Picker approach to create a problem score, based on the four original response categories. ${ }^{12}$ As independent variables we considered hospital characteristics, grouping on the quality improvement maturity classification, country and ward level. Two countries contributed data for only a few hospitals (the Netherlands: $\mathrm{n}=10$, the UK: $\mathrm{n}=14$ ) so we excluded them from the analysis. We used univariate and bivariate statistics to describe the extent to which European hospitals had implemented strategies to improve patient-centredness, and assessed associations with independent variables using the $\chi^{2}$ test (Pearson $\chi^{2}$ and linear-by-linear association for assessment of rank). We then used binary logistic regression (stepwise, entry of variables at 0.05 , removal at 0.1 ) to test the hypothesis that the implementation of strategies to improve patient-centredness is associated with hospital characteristics such as maturity of the hospital's quality management system, ownership, type, ward, and country effects.

\section{RESULTS}

Of the 389 hospitals that participated in the MARQuIS project, 351 contributed usable data for our classification of quality improvement maturity. Table 1 provides an overview of the distribution of hospitals by criteria such as ownership, type, size, and maturity group. 
Table 1 Hospital characteristics by maturity classification

\begin{tabular}{|c|c|c|c|c|c|}
\hline Characteristics & $\begin{array}{l}\text { Total } \\
(\mathrm{N}=351) \\
\mathrm{n}(\%)\end{array}$ & $\begin{array}{l}\text { High maturity } \\
(\mathrm{N}=87) \\
\mathrm{n}(\%)\end{array}$ & $\begin{array}{l}\text { Intermediate maturity } \\
\text { ( } \mathrm{N}=177) \\
\mathrm{n}(\%)\end{array}$ & $\begin{array}{l}\text { Low maturity } \\
\text { (N = 87) } \\
n(\%)\end{array}$ & p Value* \\
\hline Ownership & & & & & 0.006 \\
\hline Public & $271(80.9)$ & $61(76.3)$ & $130(76.9)$ & $80(93.0)$ & \\
\hline Private not-for-profit & $34(10.1)$ & $8(10.0)$ & $24(14.2)$ & $2(2.3)$ & \\
\hline Private for-profit & $30(9.0)$ & $11(13.8)$ & $15(8.9)$ & $4(4.7)$ & \\
\hline Total & $335(100)$ & $80(100)$ & $169(100)$ & $86(100)$ & \\
\hline Hospital type & & & & & 0.364 \\
\hline University hospital & $78(23.6)$ & $18(23.1)$ & $42(25.3)$ & $18(20.9)$ & \\
\hline $\begin{array}{l}\text { General, residency } \\
\text { training }\end{array}$ & $163(49.4)$ & $31(39.7)$ & $85(51.2)$ & $47(54.7)$ & \\
\hline General, non-teaching & $89(27.0)$ & $29(37.2)$ & $39(23.5)$ & $21(24.4)$ & \\
\hline Total & $330(100)$ & $78(100)$ & $166(100)$ & $86(100)$ & \\
\hline Hospital beds & & & & & 0.091 \\
\hline$<200$ & $60(18.8)$ & $18(23.4)$ & $26(16.1)$ & $16(19.5)$ & \\
\hline $200-399$ & $97(30.3)$ & $23(29.9)$ & $53(32.9)$ & $21(25.6)$ & \\
\hline $400-599$ & 63 (19.7) & 13 (16.9) & $33(20.5)$ & 17 (20.7) & \\
\hline $600-799$ & $38(11.9)$ & 14 (18.2) & $19(11.8)$ & $5(6.1)$ & \\
\hline $800-999$ & $22(6.9)$ & $2(2.6)$ & $13(8.1)$ & $7(8.5)$ & \\
\hline$>999$ & $40(12.5)$ & $7(9.1)$ & $17(10.6)$ & $16(19.5)$ & \\
\hline Total & $320(100)$ & $77(100)$ & $161(100)$ & $82(100)$ & \\
\hline
\end{tabular}

*Pearson $\chi^{2}$ test (linear-by-linear association for assessment of rank).

Of the 351 hospitals included, the majority (271, 80.9\%) were under public ownership. We observed significant differences in the distribution of hospital ownership by maturity classification $(p=0.006)$. Private for-profit hospitals were more strongly represented in the group with a high maturity classification $(13.8 \%)$, whereas private not-for-profit hospitals were almost absent in the group with a low maturity classification $(2.3 \%)$; however, the absolute numbers were very low. The distribution of hospital type was more homogeneous, but did differ significantly; about a half of the hospitals (49.4\%) were characterised as general hospitals with residency training, and about one quarter each either university (23.6\%) or nonteaching hospitals (27\%). The number of hospital beds ranged widely from $<200$ to $>999$ beds. In our study, hospital size (number of beds) was not clearly related to the maturity classification.

Table 2 summarises the data on the implementation of strategies to improve patient-centredness at the hospital level

Table 2 Hospital-wide implementation of strategies to improve patient-centredness by maturity classification

\begin{tabular}{|c|c|c|c|c|c|}
\hline $\begin{array}{l}\text { Domain } \\
\text { Item }\end{array}$ & $\begin{array}{l}\text { Total (\%) } \\
\mathrm{n}=351\end{array}$ & $\begin{array}{l}\text { High maturity }(\%) \\
(\mathrm{n}=87)\end{array}$ & $\begin{array}{l}\text { Intermediate maturity }(\%) \\
(\mathrm{n}=177)\end{array}$ & $\begin{array}{l}\text { Low maturity }(\%) \\
\text { ( } \mathrm{n}=87)\end{array}$ & p Value* \\
\hline \multicolumn{6}{|l|}{ Patients' rights } \\
\hline Patients' rights posted & 85.5 & 85.9 & 87.4 & 81.4 & 0.403 \\
\hline Consultation and treatment rooms allow privacy & 97.1 & 100.0 & 96.5 & 95.3 & 0.067 \\
\hline Written policy on confidentiality & 85.0 & 96.5 & 86.5 & 70.6 & $<0.001$ \\
\hline \multicolumn{6}{|l|}{ Patient information and empowerment } \\
\hline Written policies for informed consent & 93.0 & 95.3 & 95.3 & 85.9 & 0.016 \\
\hline Written policies for patient involvement & 70.6 & 89.4 & 69.4 & 53.7 & $<0.001$ \\
\hline Responsible person for health promotion & 59.9 & 86.1 & 57.3 & 39.5 & $<0.001$ \\
\hline \multicolumn{6}{|l|}{ Patient involvement in quality management } \\
\hline Involved in development of criteria or standards & 21.4 & 38.5 & 18.4 & 11.1 & $<0.001$ \\
\hline Involved in design of protocols & 19.3 & 28.9 & 18.2 & 12.3 & 0.009 \\
\hline Involved in evaluation of quality objectives & 35.1 & 51.3 & 30.3 & 29.1 & 0.004 \\
\hline Involved in participation in quality committee & 30.1 & 33.8 & 24.2 & 38.5 & 0.533 \\
\hline Involved in participation in improvement project & 39.6 & 50.6 & 32.3 & 43.6 & 0.361 \\
\hline Involved in discussion of results of patient survey & 35.4 & 44.9 & 30.6 & 35.8 & 0.242 \\
\hline \multicolumn{6}{|l|}{ Learning from patients } \\
\hline $\begin{array}{l}\text { Internal quality improvement includes monitoring } \\
\text { patients views }\end{array}$ & 65.5 & 89.5 & 64.1 & 43.4 & $<0.001$ \\
\hline $\begin{array}{l}\text { Internal quality improvement includes analysis of } \\
\text { patients' complaints }\end{array}$ & 86.3 & 96.6 & 88.4 & 71.8 & $<0.001$ \\
\hline Data on complaints reported to governing board & 91.7 & 96.4 & 94.7 & 81.0 & $<0.001$ \\
\hline $\begin{array}{l}\text { Data on monitoring patients' opinion reported to } \\
\text { governing board }\end{array}$ & 82.9 & 93.8 & 84.5 & 68.4 & $<0.001$ \\
\hline \multicolumn{6}{|l|}{ Patient hotel services } \\
\hline Possibility of obtaining a single room upon request & 63.2 & 81.9 & 59.4 & 53.2 & $<0.001$ \\
\hline Choice in timing of meals & 11.5 & 17.5 & 11.6 & 5.1 & 0.015 \\
\hline
\end{tabular}

\footnotetext{
${ }^{*}$ Pearson $\chi^{2}$ (linear-by-linear association for assessment of rank).
} 
Table 3 Ward-specific implementation of patient-centredness strategies by maturity classification

\begin{tabular}{|c|c|c|c|c|c|}
\hline \multirow{2}{*}{$\begin{array}{l}\text { Domain } \\
\text { Item }\end{array}$} & \multirow[b]{2}{*}{ Ward } & \multicolumn{3}{|c|}{ Maturity classification (\%) } & \multirow{2}{*}{$\begin{array}{l}\text { p Value for } \\
\text { difference in } \\
\text { maturity } \\
\text { classification* }\end{array}$} \\
\hline & & High & Intermediate & Low & \\
\hline \multicolumn{6}{|l|}{ Patients' rights } \\
\hline \multirow{3}{*}{$\begin{array}{l}\text { Patients give written consent to } \\
\text { treatment }\end{array}$} & AMI & 68.7 & 67.5 & 53.1 & 0.059 \\
\hline & Appendicitis & 81.7 & 72.5 & 66.7 & 0.114 \\
\hline & $\mathrm{p}$ Value ward difference $\dagger$ & 0.076 & 0.334 & 0.081 & \\
\hline \multirow{3}{*}{$\begin{array}{l}\text { Consultation and treatment allow } \\
\text { privacy }\end{array}$} & AMI & 73.9 & 66.9 & 63.4 & 0.378 \\
\hline & Appendicitis & 74.0 & 75.2 & 67.1 & 0.410 \\
\hline & $\mathrm{p}$ Value ward difference & 0.994 & 0.108 & 0.625 & \\
\hline \multicolumn{6}{|l|}{ Patient information and empowerment } \\
\hline \multirow{3}{*}{$\begin{array}{l}\text { Ability to inform foreign patients } \\
\text { about their condition and treatment }\end{array}$} & AMI & 50.7 & 42.5 & 34.7 & 0.394 \\
\hline & Appendicitis & 45.8 & 40.4 & 25.7 & 0.119 \\
\hline & $\mathrm{p}$ Value ward difference & 0.811 & 0.354 & 0.784 & \\
\hline \multirow{3}{*}{$\begin{array}{l}\text { Patients informed at discharge } \\
\text { about follow-up care }\end{array}$} & AMI & 89.0 & 94.3 & 93.8 & 0.326 \\
\hline & Appendicitis & 94.7 & 94.7 & 89.9 & 0.325 \\
\hline & $\mathrm{p}$ Value ward difference & 0.210 & 0.867 & 0.360 & \\
\hline \multicolumn{6}{|l|}{ Learning from patients } \\
\hline \multirow[t]{3}{*}{ Patients invited to express opinion } & AMI & 36.8 & 33.8 & 33.3 & 0.874 \\
\hline & Appendicitis & 44.0 & 38.3 & 36.3 & 0.586 \\
\hline & $\mathrm{p}$ Value ward difference & 0.370 & 0.403 & 0.698 & \\
\hline \multirow{3}{*}{$\begin{array}{l}\text { Patients informed about } \\
\text { complaints procedure }\end{array}$} & AMI & 80.0 & 66.0 & 59.8 & 0.021 \\
\hline & Appendicitis & 89.5 & 71.7 & 50.0 & $<0.001$ \\
\hline & p Value ward difference & 0.105 & 0.280 & 0.212 & \\
\hline \multicolumn{6}{|l|}{ Patient hotel services } \\
\hline \multirow[t]{3}{*}{ Single room on request } & AMI & 65.2 & 45.2 & 42.7 & 0.011 \\
\hline & Appendicitis & 62.0 & 47.3 & 44.3 & 0.063 \\
\hline & $\mathrm{p}$ Value ward difference & 0.699 & 0.711 & 0.836 & \\
\hline \multirow[t]{3}{*}{ Choice in timing of meals } & AMI & 11.6 & 10.2 & 2.4 & 0.070 \\
\hline & Appendicitis & 16.4 & 8.4 & 3.8 & 0.025 \\
\hline & $\mathrm{p}$ Value ward difference & 0.407 & 0.596 & 0.609 & \\
\hline
\end{tabular}

according to the maturity classification. In general, hospitals in the high maturity group reported better implementation of strategies to improve patient-centredness, and we observed significant differences for 13 of the 18 items. Considering items related to patients' rights, we observed an overall high selfreported implementation rate for posting patients' rights $(85.5 \%)$ and written policies for confidentiality (85\%), with significant differences by maturity grouping only for the latter. Almost all hospitals reported that in general, consultation and treatment rooms allowed privacy. With regard to patient information and empowerment, we observed that informed consent policies appeared to be widely implemented; however, policies for patient involvement and responsibilities for health promotion appeared to be much less common. Hospitals in the more mature groups were significantly more likely to have implemented such strategies.

Patient involvement in quality management was not a common strategy among the hospitals participating in our study, and appeared to be associated with the maturity classification only for selected items. We detected clear differences between maturity classification groups in the extent to which hospitals reported "learning from patients": hospitals in the most mature group were much more likely to report learning from patients than hospitals in the remaining groups.
One exception was handling patients' complaints, which in general were reported to the hospitals' governing board irrespective of maturity classification. Finally, with regard to patient hotel services we observed that single beds on request and choice in timing of meals were significantly associated with maturity classification; it is worth noting though that in general only $11.5 \%$ of all hospitals offered a choice in the timing of meals.

Table 3 summarises the cross-tabulations of the implementation of patient-centredness strategies at the ward level by maturity classification. We report the results of $\chi^{2}$ tests with correction for rank for differences between maturity classification, and $\chi^{2}$ tests for differences between wards.

These analyses confirmed the associations between strategies to improve patient-centredness and the revised maturity classification grouping at the hospital level (table 2). In other words, hospitals in the most mature group consistently reported better implementation of patient-centredness strategies, even though this trend was not always statistically significant. Nevertheless, the association appeared to be weaker at the ward level than at hospital level. For example, although almost all hospitals reported hospital-wide strategies to ensure privacy, the statement that "consultation and treatment allow privacy" was much less frequently answered in the affirmative at the ward 
Table 4 Crude and adjusted ward-specific implementation of patient-centredness strategies

\begin{tabular}{|c|c|c|c|c|}
\hline \multirow[b]{2}{*}{$\begin{array}{c}\text { Domain } \\
\text { Item }\end{array}$} & \multicolumn{2}{|l|}{ Crude maturity classification } & \multicolumn{2}{|c|}{ Adjusted* maturity classification } \\
\hline & $\begin{array}{l}\text { High }=1 \\
\text { Intermediate: OR (95\% CI) } \\
\text { Low: OR (95\% CI) }\end{array}$ & p Value $\dagger$ & $\begin{array}{l}\text { High }=1 \\
\text { Intermediate: OR (95\% CI) } \\
\text { Low: OR }(95 \% \mathrm{CI})\end{array}$ & p Value $\dagger$ \\
\hline \multicolumn{5}{|l|}{ Patients' rights } \\
\hline \multirow{3}{*}{$\begin{array}{l}\text { Patients give written consent } \\
\text { to treatment }\end{array}$} & 1 & 0.012 & 1 & 0.645 \\
\hline & $1.6(1.1$ to 2.3$)$ & & $1.3(0.8$ to 2.2$)$ & \\
\hline & $2.1(1.2$ to 3.4$)$ & & $1.2(0.6$ to 2.6$)$ & \\
\hline \multirow{3}{*}{$\begin{array}{l}\text { Consultation and treatment } \\
\text { allow privacy }\end{array}$} & 1 & 0.231 & 1 & 0.175 \\
\hline & $1.3(0.9$ to 2.0$)$ & & $1.5(1.0$ to 2.4$)$ & \\
\hline & $1.5(0.9$ to 2.5$)$ & & $1.5(0.8$ to 2.7$)$ & \\
\hline \multicolumn{5}{|l|}{$\begin{array}{l}\text { Patient information and } \\
\text { empowerment }\end{array}$} \\
\hline \multirow{3}{*}{$\begin{array}{l}\text { Ability to inform foreign } \\
\text { patients about their } \\
\text { condition and treatment }\end{array}$} & 1 & 0.001 & 1 & 0.030 \\
\hline & $1.9(1.2$ to 2.9$)$ & & $1.7(1.1$ to 2.8$)$ & \\
\hline & $2.6(1.6$ to 4.4$)$ & & $2.2(1.2$ to 3.8$)$ & \\
\hline \multirow{3}{*}{$\begin{array}{l}\text { Patients informed at } \\
\text { discharge about follow-up care }\end{array}$} & 1 & 0.434 & 1 & 0.202 \\
\hline & $1.5(0.7$ to 3.2$)$ & & $1.3(0.5$ to 3.1$)$ & \\
\hline & $1.0(0.4$ to 2.3$)$ & & $0.5(0.2$ to 1.5$)$ & \\
\hline \multicolumn{5}{|l|}{ Learning from patients } \\
\hline \multirow{3}{*}{$\begin{array}{l}\text { Patients invited to express } \\
\text { opinion }\end{array}$} & 1 & 0.548 & 1 & 0.056 \\
\hline & $1.1(0.7$ to 1.3$)$ & & $1.3(0.8$ to 2.1$)$ & \\
\hline & $1.3(0.8$ to 2.0$)$ & & $2.1(1.1$ to 4.0$)$ & \\
\hline \multirow{3}{*}{$\begin{array}{l}\text { Patients informed about the } \\
\text { complaints procedure }\end{array}$} & 1 & $<0.001$ & 1 & $<0.001$ \\
\hline & $1.8(1.2$ to 2.7$)$ & & $1.8(1.1$ to 2.7$)$ & \\
\hline & $4.6(2.7$ to 7.8$)$ & & $3.7(2.0$ to 7.0$)$ & \\
\hline \multicolumn{5}{|l|}{ Patient hotel services } \\
\hline \multirow[t]{3}{*}{ Single room upon request } & 1 & 0.001 & 1 & $<0.001$ \\
\hline & $1.1(0.8$ to 1.6$)$ & & $1.1(0.7$ to 3.8$)$ & \\
\hline & $2.3(1.4$ to 3.6$)$ & & $3.2(1.7$ to 3.1$)$ & \\
\hline \multirow[t]{3}{*}{ Choice in timing of meals } & 1 & 0.006 & 1 & 0.060 \\
\hline & $3.2(1.2$ to 8.4$)$ & & $2.6(1.0$ to 7.1$)$ & \\
\hline & $5.1(1.9$ to 13.9$)$ & & $3.7(1.3$ to 10.8$)$ & \\
\hline
\end{tabular}

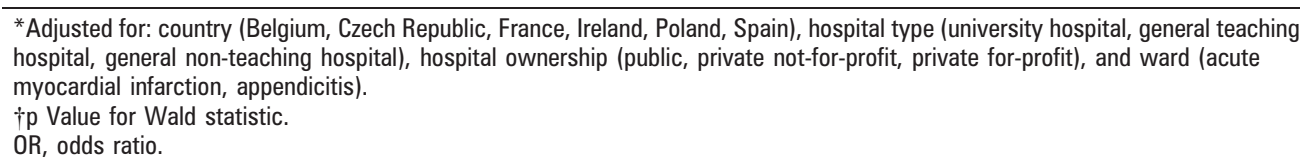

level than at the hospital level—even in the most mature groups (73.9\% for AMI, and $74.0 \%$ for appendicitis). Similar differences in reporting at the hospital and ward level were observed for the other items. Implementation of strategies to learn from patients was low. In the most mature group only 36.8\% (for AMI) and $44.0 \%$ (for appendicitis) of wards reported that "patients are invited to express opinions". The data suggest that there were no systematic differences in the way hospitals implemented patient-centredness strategies among wards, since none of the differences observed at the ward level was statistically significant.

Table 4 presents the results of logistic regression analysis to estimate the implementation of patient-centredness strategies at the ward level by maturity classification, hospital type, hospital ownership and ward type. The last column shows the association of patient-centredness strategies by maturity classification, adjusted for the remaining hospital characteristics and country. The odds ratios (ORs) reported in the table reflect implementation deficiencies, which means that higher ORs suggest that a given strategy was less likely to be implemented.
For the maturity classification we observed a general negative association of implementation with intermediate or low maturity, with hospitals in the high maturity classification used as the reference group. For example, hospitals with intermediate and low maturity classification were, respectively, 1.6 (95\% CI 1.1 to 2.3 ) and 2.1 (95\% CI 1.2 to 3.4 ) times less likely to ensure patients' written consent for treatment. The results for hospital type were more ambiguous. For example, university hospitals appeared less likely to provide comprehensive information about the patient's condition and treatment than general teaching (OR $0.5 ; 95 \% \mathrm{CI} 0.3$ to 0.7 ) and nonteaching hospitals (OR 0.5 ; 95\% CI 0.3 to 0.8) (data not reported in the table). On the other hand, general teaching and non-teaching hospitals were less likely to provide single rooms on request (OR 1.5; 95\% CI 1.0 to 2.3 and OR 1.9; 95\% CI 1.2 to 3.1, respectively). We observed statistically significant differences for patient-centredness strategies and type of hospital ownership for five of the eight items. With regard to wards, we observed significant differences only for one item (written consent to treatment); in general, there appeared to be no 
association with maturity classification depending on whether the ward was for AMI or appendicitis patients.

Given that some of the associations observed for type of hospital, hospital ownership, ward, and country might have confounded the association between implementation of patient-centredness strategies and the revised maturity classification, we entered these variables into a logistic regression model as controls (table 4). We observed that some of the crude associations observed for patient-centredness strategies and maturity classification disappeared after entering hospital characteristics and country into the model. Moreover, adjustment appeared to reduce the strength of association for the remaining items. Nevertheless, for "informing patients about their condition and treatment", "informing patients about the complaints procedure", and "providing single rooms on request", we continued to observe a significant positive association with the revised maturity classification.

\section{DISCUSSION}

In a large sample of European hospitals, we investigated the implementation of patient-centredness and associated characteristics of hospital structure and quality management systems. In general, hospitals in the highest maturity classification group reported better implementation of strategies to improve patient-centredness, and we found significant differences for 13 out of 18 dependent variables (patient-centredness strategies) and maturity classification at the hospital level.

The absolute level of self-reported implementation differed for each of the items examined. For example, irrespective of the classification of quality improvement maturity, hospitals reported high implementation of patients' rights, but low involvement of patients in quality management issues. We also noted systematic differences in "learning from patients" through the use of surveys on patients' views, despite the widespread use of such instruments. ${ }^{27}$ Hospitals in the highly developed maturity group appeared to make better use of the knowledge generated for organisational learning and continuous improvement. The strength of association between implementation of patient-centredness strategies and maturity, however, appeared to be lower at the ward level than at the hospital level. Moreover, some of the associations detected disappeared or were weaker after adjustment for potential confounding variables.

In our final model, we detected associations between maturity classification and patient-centredness with regard to "ability to inform patients about treatment", "information to patients about the complaints procedure", and "providing a single room upon request". This suggests that the association between patient-centredness and maturity classification was confounded by country-specific quality strategies. For example, hospitals from countries with an obligatory national hospital accreditation system might have reported better implementation of some patient-centredness strategies, because these centres are also subject to national accreditation processes. ${ }^{28}$ On the other hand, it should be considered that the association between maturity classification and patient-centredness strategies seemed to be much stronger at the hospital level than at the ward level. In other words, hospitals might implement policies at a strategic level to meet legislative and accreditation requirements; however, the implementation of such polices might not be as strong at the ward level. ${ }^{29}$ The results of our study thus suggest that, although quality improvement systems appear to be effective with regard to the implementation of selected patient-centredness strategies, they are not sufficient to ensure widespread implementation of patient-centredness throughout the organisation.

Some of the findings of our study are difficult to contextualise given the lack of comparable research and the difficulty of conceptualising patient-centredness. ${ }^{30}$ Previous studies have identified differences in health system responsiveness, ${ }^{19} 3132$ and a substantial literature supports patients' concerns about the lack of patient-centredness of hospital services. ${ }^{33-35}$ However, a comparative analysis of the impact of different quality mechanisms on patient-centredness strategies (or quality strategies as a whole) at the hospital and ward level is an under-researched topic. ${ }^{36} 37$

There are a number of limitations of the study that merit discussion. First, despite the many attempts to recruit hospitals randomly, this proved unfeasible in some countries. Moreover, the number of hospitals recruited was not sufficient to make generalisable statements about the country-specific implementation of strategies to improve patient-centredness. However, in view of the regionalisation of health systems, and of common experiences with the misclassification of hospitals within countries, it was not the purpose of this study to generalise findings at the country level.

A second limitation of the study is the incomplete operationalisation of the concept of patient-centredness. For example, in our study we were not able to include dimensions of patientcentredness such as "exploring the patients' main concern" and "finding common ground and mutually agreeing on the management of the condition", as suggested by Steward et $a l,{ }^{11}$ or issues such as "emotional support" and "alleviating fear and anxiety", included in the Picker approach to assessing patient-centred care. ${ }^{12}$ The main reason for excluding these dimensions of patient-centredness was that in this project we did not collect data at the patient level. Although these concepts have been substantially examined in the literature on shared decision making ${ }^{38}$ and assessing patients' views or experiences, ${ }^{27}$ the link to quality improvement systems so far has not been studied in depth.

A third limitation of our study is that it is based on selfreported data and thus prone to the biases associated with selfassessment. By comparing responses to the questionnaire and subsequent audit data, we have demonstrated reasonable agreement (MARQuIS project consortium, unpublished results, Barcelona, 2006).

A final limitation is the lack of outcome measures on the actual views of patient regarding patient-centredness at hospitals that participated in the study. In light of the undeniable importance of including the patients' views in a study of patient-centredness, we draw readers' attention to recent calls in the literature to address the "forgotten" structural dimension in hospital quality management. ${ }^{39} 40$ Despite these shortcomings, we believe that the provisional results presented in this article are an important contribution to the debate on the evaluation of quality improvement systems, and to the particular focus on improving patient-centredness.

From a policy perspective, the widespread implementation of policies to ensure patients' rights, privacy, and confidentiality is noteworthy. Patient involvement in quality improvement activities, on the other hand, so far appears to be a more rhetorical exercise than a practice. ${ }^{41}$ Moreover, the contextual meaning of patient involvement in quality improvement activities in different hospitals and different countries needs to be explored further. A tentative finding of the study is that more mature quality improvement systems appear to be positively associated with the implementation of several 
strategies to improve patient-centredness. The findings are weak in the sense that they appear to be confounded by certain hospital characteristics and national quality strategies, and associations are more likely to be detected at the strategic level, whereas the strength of association is reduced at the ward level. Moreover, the association appears to be significant only for selected items of patient-centredness, and the question remains of how to ensure the implementation of a broad vision of patient-centred care. ${ }^{42}$ From a research perspective, it should be emphasised that the link between strategies to improve patientcentredness and the maturity of the hospital quality improvement classification is not yet well understood, and that substantial further research is required to understand these links. Further research should address the development of a score of patient-centredness strategies, and conduct comparisons of hospitals that implement strategies successfully across wards and those that adopt strategies only at the hospital policy level.

\section{CONCLUSION}

This article presents the findings of a study of the implementation of strategies to improve patient-centredness in European hospitals, and the association between these strategies and the development of a hospital's quality improvement system. On the one hand, some patient-centredness strategies appear to be widely implemented, such as patients' rights and privacy; on the other hand, strategies on patients' involvement in quality improvement activities, and strategies to learn from patients, are not widely implemented. Although several patient-centredness strategies appear to be positively associated with the development of hospital quality improvement systems (such as providing information on the patient's condition and treatment, information on complaints procedures and single rooms on request), other strategies appear to be confounded by hospital characteristics and different national or regional quality strategies.

Funding: This research was funded by the European Commission through its "Scientific Support to Policies" action under the Sixth Framework Programme for Research for the research project "Methods of Assessing Response to Quality Improvement Strategies (MARQuIS)" (SP21-CT-2004-513712).

Competing interests: None.

\section{REFERENCES}

1. The Joint Commission. "What did the doctor say?" Improving health literacy to protect patient safety. Health Care at the Crossroads reports. Oakbrook Terrace, IL: The Joint Commission, 2007,

2. Coulter A, Ellins J. Effectiveness of strategies for informing, educating, and involving patients. BMJ 2007;335:24-7.

3. Lorig KR, Ritter P, Stewart AL, et al. Chronic disease self-management program: 2year health status and health care utilization outcomes. MedCare 2001;39:1217-23.

4. Groene 0, Garcia-Barbero M. Health promotion in hospitals: evidence and quality management. Copenhagen: WHO Regional Office for Europe, 2005

5. Bikker AP, Thompson AGH. Predicting and comparing patient satisfaction in four different modes of health care across a nation. Soc Sci Med 2006;63:1671-83.

6. Donabedian A. The Lichfield Lecture. Quality assurance in health care: consumers' role. Qual Health Care 1992;1:247-51.

7. Institute of Medicine. Crossing the quality chasms: a new health system for the 21st century. Washington, DC: Institute of Medicine, 2001.

8. Engel G. The need for a new medical model: a challenge for biomedicine. Science 1977;196:129-36.

9. Balint E. The possibilities of patient-centred medicine. J Royal Coll Gen Prac 1969;17:269-76.

10. Stewart $\mathbf{M}$. Towards a global definition of patient centred care. BMJ 2001;322:444-5

11. Stewart AL, Brown JB, Weston WW, et al. Patient-centred medicine: transforming the clinical method. Oxford: Radcliffe Medical Press, 2003.

12. Jenkinson C, Coulter A, Bruster S. The Picker Patient Experience Questionnaire: development and validation using data from in-patient surveys in five countries. Int J Qual Health Care 2002;14:353-8.
13. Little $\mathbf{P}$, Everitt $H$, Williamson I, et al. Observational study of effect of patient centredness and positive approach on outcomes of general practice consultations. BMJ 2001;323:908-11.

14. Barry C, Bradley CP, Britten N, et al. Patients' unvoiced agendas in general practice consultations: qualitative study. BMJ 2000;320:1246-50.

15. Britten N, Stevenson FA, Barry CA, et al. Misunderstandings in prescribing decisions in general practice: qualitative study. BMJ 2000;320:484-8.

16. Law S, Britten N. Factors that influence the patient centredness of a consultation Br J Gen Pract 1995:45:520-4.

17. McGlynn EA, Asch SM, Adams J, et al. The quality of health care delivered to adults in the United States. N Engl J Med 2003;348:2635-45.

18. Towle A, Godolphin W, Grams G, et al. Putting informed and shared decision making into practice. Health Expect 2006;9:321-32.

19. Schoen C, Osborn R, Huynh PT, et al. Taking the pulse of health care systems: experiences of patients with health problems in six countries. Health Aff (Millwood) 2005; Suppl Web Exclusives: W5-25.

20. Towle A, Godolphin W, Manklow J, et al. Patient perceptions that limit a community-based intervention to promote participation. Patient Educ Couns 2003:50:231-3.

21. Johnson A, Baum F. Health promoting hospitals: a typology of different organizational approaches to health promotion. Health Promot Int 2001;16:281-7.

22. Lombarts MJMH, Rupp I, Vallejo P, et al. Application of quality improvement strategies in 389 European hospitals: results of the MARQulS project. Qual Saf Health Care 2009;18(Suppl I):i28-37.

23. Spencer $\mathbf{E}$, Walshe K. National quality improvement policies and strategies in European healthcare systems. Qual Saf Health Care 2009;18(Suppl I):i22-7.

24. Suñol R, Garel P, Jacquerye A. Cross-border care and healthcare quality improvement in Europe: the MARQulS research project. Qual Saf Health Care 2009;18(Suppl I):i3-7

25. Groene 0, Poletti $\mathrm{P}$, Vallejo $\mathrm{P}$, et al. Quality requirements for cross-border care in Europe: a qualitative study of patients', professionals' and healthcare financiers' views. Qual Saf Health Care 2009;18(Suppl I):i15-21.

26. Lombarts MJMH, Rupp I, Vallejo P, et al. Differentiating between hospitals according to the "maturity" of quality improvement systems: a new classification scheme in a sample of European hospitals. Oual Saf Health Care 2009;18(Suppl I):i38-43.

27. Organisation for Economic Co-operation and Development. National and crossnational surveys of patient experiences: a structured review. Report prepared by the Norwegian Centre for the Health Services, 2008. www.oecd.org/dataoecd/43/58/ 39493930.pdf (accessed 13 Jul 2008).

28. Dickson EK, Ashton J, Smith JM. Does setting adolescent-friendly standards improve the quality of care in clinics? Evidence from South Africa. Int J Oual Health Care 2007;19:80-9.

29. Suñol R, Vallejo P, Thompson A, et al. Impact of quality strategies on hospital outputs. Qual Saf Health Care 2009;18(Suppl I):157-63.

30. Lewin SA, Skea ZC, Entwistle V, et al. Interventions for providers to promote a patient-centred approach in clinical consultations. Cochrane Database Syst Rev 2001; (4):CD003267.

31. Coulter A, Jenkinson C. European patients' views on the responsiveness of health systems and healthcare providers. Eur J Public Health 2005;15:355-60.

32. Coulter A, Magee $\mathrm{H}$. The European patient of the future. Oxford: Open University Press, 2003.

33. Mead N, Bower P. Patient-centredness: a conceptual framework and review of the empirical literature. Soc Sci Med 2000;51:1087-100.

34. Groene 0, Jorgensen SJ. Health promotion in hospitals - a strategy to improve quality in health care. Eur J Public Health 2005;15:6-8

35. McPherson CJ, Higginson IJ, Hearn J. Effective methods of giving information in cancer: a systematic literature review of randomized controlled trials. J Public Health Med 2001;23:227-34

36. Braithwaite J, Westbrook J, Pawsey M, et al. A prospective, multi-method, multi-disciplinary, multi-level, collaborative, social-organisational design for researching health sector accreditation (LP0560737). BMC Health Serv Res 2006;6:113.

37. Weiner BJ, Alexander JA, Shortell SM, et al. Quality improvement implementation and hospital performance on quality indicators. Health Serv Res 2006;41:307-34.

38. Dy SM. Instruments for evaluating shared medical decision making: a structured literature review. Med Care Res Rev 2007;64:623-49.

39. Glickman SW, Bagget KA, Krubert $\mathrm{CH}$, et al. Promoting quality: the health-care organization from a management perspective. Int J Oual Health Care 2007;19:341-48.

40. Hogg W, Rowan $M$, Russell G, et al. Framework for primary care organizations: the importance of a structural domain. Int J Qual Health Care 2008, Advance Access published on 13 June 2008; doi: doi:10.1093/intqhc/mzm054.

41. Coulter A. Engaging patients in their health care: how is the UK doing relative to other countries. Oxford: Picker Institute Europe, 2006. http://www.pickereurope.org/ Filestore/Publications/Six_country_study_with_ISBN_web.pdf (accessed 13 Jul 2008).

42. Shaller D. Patient-centered care: what does it take. New York: The Commonwealth Fund, 2007. www.commonwealthfund.org/usr doc/Shaller patientcenteredcarewhatdoesittake 1067.pdf?section = 4039 (accessed 13 Jul 2008). 